\title{
Lower Urinary Tract Symptoms and Erectile Dysfunction in Men With Type 2 Diabetes Mellitus
}

\author{
Hyo Jeong Song, Eun Joo Lee, Nancy Bergstrom ${ }^{1}$, Duck-Hee Kang ${ }^{1}$, Dae Ho Lee ${ }^{2}$, Gwangpyo Koh ${ }^{3}$, Jung-Sik Huh', \\ Sung Dae Kim ${ }^{4}$, Seong Cheol Hong ${ }^{5}$, Seong Sil Moon, Jiyoung Kang ${ }^{6}$ \\ Department of Nursing, Jeju National University College of Nursing, Jeju, Korea; \\ ${ }^{1}$ University of Texas Health Science Center at Houston, School of Nursing, Houston, TX, USA; \\ ${ }^{2}$ Department of Internal Medicine, Wonkwang University School of Medicine \& Hospital, Iksan; \\ Departments of ${ }^{3}$ Internal Medicine, ${ }^{4}$ Urology, and ${ }^{5}$ Preventive Medicine, Jeju National University College of Medicine, Jeju; \\ ${ }^{6}$ Doctoral Student, Seoul National University College of Nursing, Seoul, Korea
}

Purpose: To assess the prevalence of lower urinary tract symptoms (LUTS) and erectile dysfunction (ED) and the relationships between LUTS, ED, depression, and other factors in Korean men with type 2 diabetes mellitus (T2DM).

Methods: This cross-sectional study included 124 male patients with T2DM who attended a university hospital diabetes clinic between October 2010 and April 2012. Data were collected using structured interviews and chart reviews. LUTS were measured using the International Prostate Symptom Score (IPSS), ED using the five-item Korean version of the International Index of Erectile Function (IIEF), depression using the Center for Epidemiologic Studies Depression Scale, and glycosylated hemoglobin level from clinical data.

Results: The IPSS score was $9.2 \pm 6.6$. The total IPSS scores indicated that $53.3 \%$ of the subjects had either moderate or severe symptoms. The mean IIEF score was $7.3 \pm 8.6$, indicating the severity of ED to be mild, mild to moderate, moderate, and severe in $10.5 \%, 9.7 \%, 1.6 \%$, and $66.9 \%$ of the participants, respectively. LUTS showed a significant negative correlation with ED $(\mathrm{r}=-0.26, \mathrm{P}=0.003)$ and a significant positive correlation with depression $(\mathrm{r}=0.33, \mathrm{P}<0.001)$. ED was negatively correlated with age $(r=-0.44, \mathrm{P}<0.001)$, duration of diabetes $(\mathrm{r}=-0.26, \mathrm{P}=0.004)$, and depression $(\mathrm{r}=-0.24, \mathrm{P}=0.008)$.

Conclusions: LUTS and ED were found to have a high prevalence among Korean men with T2DM. More severe ED was associated with worse LUTS, whereas more severe depressive symptoms were found to be associated with more severe ED and LUTS.

Keywords: Lower urinary tract symptoms; Erectile dysfunction; Type 2 diabetes mellitus; Depression

\section{INTRODUCTION}

Diabetes mellitus is a significant global health concern, and its prevalence has been rising steadily over recent decades, especially in Asia [1,2]. The prevalence of type 2 diabetes mellitus (T2DM) has increased significantly in South Korea [3,4]. According to Korea Health Statistics (2010) [5], the prevalence of diabetes in South Korea was $10.1 \%$ among adults older than 30 years and $22.7 \%$ among adults older than 65 years.

It is well known that diabetes mellitus is a chronic metabolic condition that is associated with numerous complications [6].
Lower urinary tract symptoms (LUTS) are common in adults with diabetes mellitus and cause a considerable health burden for patients [2,7]. The impact of diabetes mellitus on the lower urinary tract is multifactorial and includes osmolarity diuresis, metabolic perturbations, and microvascular damage. Neuropathy caused by diabetes mellitus may lead to dysfunction of the smooth muscle, urothelium, and neuronal components of the bladder $[8,9]$. The development of LUTS, and the underactivity or overactivity of the detrusor muscle are common symptoms associated with diabetes progression [8]. Lee et al. [10] reported that female patients with diabetes had significantly higher noc-
Corresponding author: Hyo Jeong Song

Department of Nursing, Jeju National University College of Nursing, 102 Jejudaehak-ro, Jeju 690-756, Korea

Tel: +82-64-754-3885 / Fax: +82-64-702-2686 / E-mail: hjsong@jejunu.ac.kr Submitted: October 3, 2013 / Accepted after revision: November 5, 2013
This is an Open Access article distributed under the terms of the Creative Commons Attribution Non-Commercial License (http://creativecommons.org/licenses/by-nc/3.0/) which permits unrestricted non-commercial use, distribution, and reproduction in any medium, provided the original work is properly cited. 
turia scores, weaker urinary streams, and lower voided volumes compared with nondiabetic women.

Erectile dysfunction (ED) is a common occurrence in diabetic men [11]. In a multicenter study, Cho et al. [12] found that the overall prevalence of ED was $65.4 \%$ in Korean men with T2DM. Lu et al. [13] showed that the prevalence of ED was $83.6 \%$ (severe $\mathrm{ED}, 43.2 \%$ ) among Taiwanese men with T2DM when assessed using the International Index of Erectile Function (IIEF5) questionnaire. ED occurs at an earlier age in diabetic men in comparison with the general population [14,15]. Taken together, LUTS and ED are highly prevalent and burdensome conditions among men with T2DM; however, most care providers have failed to pay sufficient attention to the treatment of these conditions. Early detection and efficient management may minimize the negative impact of LUTS and ED on quality of life.

Previous epidemiological studies have suggested that LUTS are strongly associated with ED [16,17]. Depressive symptoms are more prevalent among individuals with T2DM than among nondiabetic individuals [18]. In addition, surveys have demonstrated that depression is strongly associated with LUTS [19] and ED [11]. These findings suggest that a comprehensive assessment of the relationship between LUTS, ED, depression, and diabetic factors is necessary.

The purpose of this study was therefore to assess the prevalence of LUTS and ED and the relationships between LUTS, ED, depression, duration of diabetes, and $\mathrm{HbAlc}$ levels in men with T2DM.

\section{MATERIALS AND METHODS}

\section{Study Design}

Cross-sectional study with one-time data collection

\section{Study Participants and Data Collection}

Between October 2010 and April 2012, 124 men with T2DM who attended the Diabetes Outpatient Clinic of the National University Hospital, Jeju, South Korea, were recruited. The inclusion criteria were male sex, age $>40$ years, diagnosis of T2DM, and receiving pharmacological treatment for diabetes. Data were collected via face-to-face interviews conducted by the principal investigator and a well-trained research assistant who explained the study purpose and data collection method to the subjects individually. Interviews were conducted using a standardized questionnaire, and written informed consent was obtained before data collection was initiated. Interviews were per- formed in a quiet room in the hospital, and the questionnaire took approximately 20 minutes to complete. Each patient's medical records were reviewed to collect information relating to other diabetic factors, including duration of T2DM, metabolic control as measured by HbAlc levels, and concurrent medical conditions. The study protocol was approved by the institutional review board of Jeju National University Hospital.

\section{Measures}

A structured questionnaire was used as guide in the interviews. The subjects were asked about their general characteristics (e.g., age and living arrangements). Body mass index (weight $[\mathrm{kg}] /$ height $\left[\mathrm{m}^{2}\right]$ ) was calculated on the basis of height and weight.

Symptoms of depression were assessed using the Korean language version of the Center for Epidemiologic Studies Depression Scale (CES-D) [20], a 20-item, four-point Likert scale that includes questions relating to how often the subject felt or behaved in a particular manner within the preceding week. Scores range from 0 (not at all depressed) to 60 (very depressed), with a cutoff score of 21 as an indicator of major depressive symptoms [21]. Cronbach's $\alpha$ for the CES-D scale was 0.90 in this study.

LUTS were assessed using the Korean version of the International Prostate Symptom Score (IPSS) [22]. The IPSS includes seven LUTS indicators, including four voiding symptoms (straining, intermittency, weak stream, and incomplete emptying) and three storage symptoms (frequency, urgency, and nocturia). The subjects were asked to indicate the frequency of each of the seven symptoms over the preceding 6 months. Each symptom is graded from 0 (not at all) to 5 (almost always) according to the frequency of occurrence. Scores from the individual symptoms were aggregated to obtain a total IPSS score, which ranges from 0 to 35 and is categorized as either mild (0-7), moderate (8-19), or severe (20-35). Cronbach's $\alpha$ for the LUTS scale was 0.69 in this study.

$\mathrm{ED}$ in men with $\mathrm{T} 2 \mathrm{DM}$ was assessed using the Korean version of the IIEF-5 [23]. The IIEF-5 evaluates five items relating to sexual function. Each item is rated on a 6-point scale (between 0 and 5), except for one item that was rated on a fivepoint scale (between 1 and 5). The subjects were asked to indicate the frequency of each of the five symptoms during the preceding 6 months. A total score, ranging from 1 to 25 , was calculated by adding the score for each individual item. A score between 22 and 25 was considered to represent normal function; a score between 17 and 21, mild ED; and a score < 17, significant ED. Scores indicating significant cases of ED can be further 
subdivided into mild to moderate ED (12-16), moderate ED (8-11), and severe ED $(\leq 7)$ [24]. Cronbach's $\alpha$ for the IIEF-5 scale was 0.95 in this study.

$\mathrm{HbAlc}$ levels were reviewed on the basis of blood test results, with samples collected within 3 months of clinical treatment preceding data collection.

\section{Data Analysis}

Descriptive data are reported to provide an overview of the general characteristics of the participants. The relationships between LUTS, ED, age, duration of diabetes, HbAlc levels, and depression were analyzed using Pearson correlation coefficient. A $\mathrm{P}<0.05$ was considered to be statistically significant. All statistical procedures were performed using the SAS ver. 9.2 (SAS Institute Inc., Cary, NC, USA).

\section{RESULTS}

\section{Characteristics of Participants}

A total of 124 men with T2DM were enrolled in the study. The

Table 1. General characteristics of the participants $(n=124)$

\begin{tabular}{lc}
\hline Characteristic & Value \\
\hline Age $(\mathrm{yr})$ & $64.57 \pm 9.45$ \\
$<65$ & $64(51.61)$ \\
$\geq 65$ & $60(48.39)$ \\
Living arrangements & \\
Lives without spouse & $16(12.90)$ \\
Lives with spouse & $108(87.10)$ \\
Body mass index $\left(\mathrm{kg} / \mathrm{m}^{2}\right)$ & $25.40 \pm 13.96$ \\
$<25$ & $75(60.48)$ \\
$\geq 25$ & $49(39.52)$ \\
Duration of diabetes $(\mathrm{yr})$ & $11.20 \pm 10.50$ \\
$<10$ & $68(54.84)$ \\
$\geq 10$ & $56(45.16)$ \\
HbAlc $(\%)^{\mathrm{a})}$ & $7.74 \pm 1.63$ \\
$<7$ & $37(35.24)$ \\
$\geq 7$ & $68(64.76)$ \\
Depression & $7.71 \pm 9.74$ \\
No $(<21)$ & $112(90.32)$ \\
Yes $(\geq 21)$ & $12(9.68)$ \\
\hline
\end{tabular}

Values are presented as mean \pm standard deviation or number (\%). HbA1c, glycosylated hemoglobin.

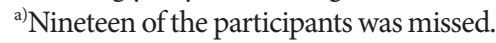

mean age of the participants was $64.6 \pm 9.5$ years, ranging from 46 to 85 years. In terms of age groups, $52 \%$ of the men were younger than 65 years and $48 \%$ were older than 65 years. Of the participants, $87 \%$ were living with a spouse. The mean body mass index (BMI) was $25.4 \mathrm{~kg} / \mathrm{m}^{2}$, and $40 \%$ of the participants had a BMI $\geq 25 \mathrm{~kg} / \mathrm{m}^{2}$ (overweight). Forty-five point two percent $(45.2 \%)$ had T2DM for $\geq 10$ years, and the mean duration of T2DM was $11.2 \pm 10.5$ years. The mean $\mathrm{HbAlc}$ level was $7.7 \% \pm 1.6 \%$, with $65 \%$ of the participants with a HbAlc level $\geq$ $7 \%$. Approximately $10 \%$ of the participants had depressive symptoms (CES-D score $>21$, Table 1).

\section{Prevalence of LUTS and ED}

The mean IPSS score was $9.2 \pm 6.5$. In terms of LUTS severity, $46.8 \%$ of the participants were in the mild group, $44.4 \%$ were in the moderate group, and $8.9 \%$ were in the severe group (Table 2 ). Of the scores of individual LUTS (range, 0-5), nocturia showed the highest score with a mean of 2.0, followed by weak stream (mean, 1.9) and incomplete bladder emptying (mean, 1.2; Table 3).

The mean IIEF-5 score for ED was 7.3 \pm 8.6. In terms of ED severity, $11.3 \%$ of the participants had no ED, $10.5 \%$ had mild $\mathrm{ED}, 9.7 \%$ had mild to moderate $\mathrm{ED}, 1.6 \%$ had moderate $\mathrm{ED}$, and $66.9 \%$ had severe ED (Table 2).

\section{Correlations Between LUTS, ED, Age, Duration of Diabetes, HbA1c Levels, and Depression}

LUTS showed a statistically significant positive correlation with depression $(\mathrm{r}=0.33, \mathrm{P}<0.001)$ and a negative correlation with

Table 2. Prevalence of lower urinary tract symptoms and erectile dysfunction $(\mathrm{n}=124)$

\begin{tabular}{lc}
\hline Characteristic & Value \\
\hline Lower urinary tract symptoms & $9.2 \pm 6.5$ \\
Mild $(0-7)$ & $58(46.77)$ \\
Moderate $(8-19)$ & $55(44.35)$ \\
Severe $(\geq 20)$ & $11(8.87)$ \\
Erectile dysfunction & $7.26 \pm 8.61$ \\
Normal $(22-25)$ & $14(11.30)$ \\
Mild $(17-21)$ & $13(10.50)$ \\
Mild to moderate $(12-16)$ & $12(9.70)$ \\
Moderate $(8-11)$ & $2(1.60)$ \\
Severe $(\leq 7)$ & $83(66.90)$ \\
\hline
\end{tabular}

Values are presented as mean \pm standard deviation or number (\%). 
$\mathrm{ED}(\mathrm{r}=-0.26, \mathrm{P}=0.003)$, indicating that diabetic men with worse LUTS tended to have more severe depression and/or worse ED.

ED was significantly negatively correlated with age $(r=-0.44$, $\mathrm{P}<0.001)$, duration of diabetes $(\mathrm{r}=-0.026, \mathrm{P}=0.004)$, and depression $(r=-0.24, P=0.008)$, indicating that older men, those with a longer duration of diabetes, and/or those with more severe depression had worse ED. LUTS and ED were not significantly correlated with $\mathrm{HbA1}$ level $(\mathrm{r}=0.13, \mathrm{P}=0.167 ; \mathrm{r}=-0.16$, $\mathrm{P}=0.875$; Table 4).

\section{DISCUSSION}

In this study, 53\% of Korean men with T2DM, with a mean age of 65 years, were found to have moderate to severe LUTS (IPSS score $>7$ ). In a study in one diabetes clinic, Wang et al. [25] reported that $30 \%$ of 226 T2DM men aged $<45$ years had moderate to severe LUTS. These results demonstrate that T2DM increases the risk of moderate to severe LUTS in both old and young individuals.

It is well known that diabetes can negatively impact on the bladder and affect the more common LUTS among diabetic male patients [26]. Over $50 \%$ of patients with diabetes have been

Table 3. Mean score of each lower urinary tract symptom $(\mathrm{n}=124)$

\begin{tabular}{lc}
\hline LUTS & Mean \pm SD \\
\hline Incomplete emptying & $1.19 \pm 1.69$ \\
Frequency & $1.19 \pm 1.64$ \\
Urgency & $1.04 \pm 1.48$ \\
Intermittency & $1.12 \pm 1.58$ \\
Weak stream & $1.91 \pm 1.86$ \\
Straining & $0.71 \pm 1.31$ \\
Nocturia & $2.02 \pm 1.40$ \\
\hline
\end{tabular}

LUTS, lower urinary tract symptoms; SD, standard deviation. found to exhibit bladder dysfunction characterized by large bladder capacity, diminished bladder sensation, poor contractility, and elevated postvoid residual urine [27]. Diabetic bladder dysfunction may be induced by diabetic neuropathy and/or diuresis associated with diabetes [28,29].

Of all seven LUTS assessed, the mean scores for nocturia and weak urinary stream were the highest. Sarma et al. [26] also reported that among the symptoms experienced by 170 men with T2DM, nocturia was the most common of the storage-related symptoms and weak stream was the most common of the voiding-related symptoms.

Similarly, nocturia and weak stream showed higher scores among women with T2DM, suggesting a similar severity of these symptoms between males and females with T2DM [26]. In particular, nocturia may have a severe impact on an individual's sleep quality, which in turn can negatively affect quality of life in T2DM patients [30]. Regular assessment is therefore required for the evaluation of each LUTS to improve quality of life for patients with T2DM. Moreover, Lee et al. [31] reported that a high LUTS score might be a good marker for the assessment of diabetic bladder dysfunction. Regular assessment and evaluation of LUTS is critical to detect urinary complications.

The mean IIEF- 5 score in this study was 7.3 , and $78 \%$ of the participants had significant ED (IIEF-5 score < 17). According to Sasaki et al. [15], 64\% of 1,118 Japanese men with T2DM (mean age, 59 years) had significant ED. Even though the mean age of their sample was slightly different, it is clear that ED is highly prevalent among T2DM men. In terms of the relationship between LUTS and ED, epidemiological community-based studies have demonstrated that LUTS are correlated with ED [16,32]. El-Sakka [33] reported that among 476 male patients with ED, there was a relationship between LUTS and both longer duration of ED and increased severity of ED, as well as between risk factors for LUTS and ED, including age and diabetes. According to Wang et al. [25], the relationship between LUTS and ED exists among younger men with T2DM. Our study also shows that

Table 4. Correlations between lower urinary tract symptoms, erectile dysfunction, age, duration of diabetes, HbAlc levels, and depression

\begin{tabular}{lcccccc}
\hline & Age & BMI & Duration of diabetes & HbAlclevel & Depression & ED \\
\hline LUTS & $0.110(0.209)$ & $-0.020(0.830)$ & $-0.010(0.982)$ & $0.13(0.167)$ & $0.330(<0.001)$ & $-0.260(0.003)$ \\
ED & $-0.440(<0.001)$ & $0.120(0.193)$ & $-0.260(0.004)$ & $-0.160(0.875)$ & $-0.240(0.008)$ & \\
\hline
\end{tabular}

Values are presented as correlation (P-value).

HbA1c, glycosylated hemoglobin; BMI, body mass index; ED erectile dysfunction; LUTS lower urinary tract symptoms. 
increased severity of LUTS in 124 men with T2DM significantly increased the severity of ED.

LUTS increase with age [16]. However, there was no obvious relationship between LUTS and age in this study. The HbA1C levels and duration of diabetes were not found to be significantly correlated with LUTS in this study.

The results of our study support the hypothesis that a longer duration of diabetes and older age lead to more severe ED. Previous studies have reported that young men with T2DM have a higher prevalence of ED [25] and that T2DM is independently associated with ED risk [12]. Early and regular assessment for ED among T2DM men may be required to improve quality of life in this group. Moreover, in this study, the prevalence of severe ED (IIEF-5 score $\leq 7$ ) was even higher, at $66.9 \%$. Given the high prevalence and severity of $\mathrm{ED}$, both health-care providers and patients should pay greater attention to the proper and early management of the condition.

Our study showed that depression among T2DM men was significantly correlated with ED and LUTS. According to the results of the Boston Area Community Health Survey conducted by Fitzgerald et al. [34], urologic and sexual symptoms are associated with depression. Moreover, the development of ED has also been found to be associated with a highly significant increase in depressive symptoms and a marked decrease in the quality of sexual life [35].

This study had several limitations. First, LUTS and ED were assessed based on self-reporting in the context of a structured interview, without any attempt to confirm diagnosis using clinical procedures. Furthermore, the study design was cross-sectional; therefore, causal relationships could not be established. For example, it is not clear whether an improvement in glycemic control, assessed here using HbAlc level, can lead to a reduction in LUTS and/or ED. In addition, the convenience sample comprised T2DM men from one diabetic clinic in one city in Korea and may therefore not be representative of the wider Korean population.

Randomized clinical trails with prospective repeated data collections are required to clarify the causal relationship between LUTS, ED, and the other factors assessed in this study.

In conclusion, the findings of this study demonstrate that LUTS and ED are highly prevalent among Korean men with T2DM. Of the LUTS tested, nocturia and weak stream were found to be the most common. Of the men studied, $66.9 \%$ had severe ED and diabetic men with more severe ED also tended to have more severe LUTS. More severe depressive symptoms were associated with the more severe ED and LUTS. Regular assessment and proper management of ED and LUTS may improve quality of life among men with T2DM.

\section{CONFLICT OF INTEREST}

No potential conflict of interest relevant to this article was reported.

\section{ACKNOWLEDGEMENTS}

This research was supported by the 2013 scientific promotion program funded by Jeju National University.

\section{REFERENCES}

1. Gu D, Reynolds K, Duan X, Xin X, Chen J, Wu X, et al. Prevalence of diabetes and impaired fasting glucose in the Chinese adult population: International Collaborative Study of Cardiovascular Disease in Asia (InterASIA). Diabetologia 2003;46:1190-8.

2. Liu RT, Chung MS, Chuang YC, Lee JJ, Lee WC, Chang HW, et al. The presence of overactive bladder wet increased the risk and severity of erectile dysfunction in men with type 2 diabetes. J Sex Med 2012;9:1913-22.

3. Wild S, Roglic G, Green A, Sicree R, King H. Global prevalence of diabetes: estimates for the year 2000 and projections for 2030. Diabetes Care 2004;27:1047-53.

4. Kim DJ. The epidemiology of diabetes in Korea. Diabetes Metab J 2011;35:303-8.

5. Korea Centers for Disease Control and Prevention. Korea Health Statistics 2010. Cheongwon: Korea Centers for Disease Control and Prevention; 2011.

6. Chiu AF, Huang MH, Wang CC, Kuo HC. Higher glycosylated hemoglobin levels increase the risk of overactive bladder syndrome in patients with type 2 diabetes mellitus. Int J Urol 2012;19:995-1001.

7. Yamasaki H, Ogawa K, Sasaki H, Nakao T, Wakasaki H, Matsumoto $\mathrm{E}$, et al. Prevalence and risk factors of erectile dysfunction in Japanese men with type 2 diabetes. Diabetes Res Clin Pract 2004;66 Suppl 1:S173-7.

8. Yoshimura N, Chancellor MB, Andersson KE, Christ GJ. Recent advances in understanding the biology of diabetes-associated bladder complications and novel therapy. BJU Int 2005;95:733-8.

9. Kebapci N, Yenilmez A, Efe B, Entok E, Demirustu C. Bladder dysfunction in type 2 diabetic patients. Neurourol Urodyn 2007;26: 814-9. 
10. Lee WC, Wu HP, Tai TY, Liu SP, Chen J, Yu HJ. Effects of diabetes on female voiding behavior. J Urol 2004;172:989-92.

11. Henis O, Shahar Y, Steinvil A, Finn T, Heruti R, Loewenstein A, et al. Erectile dysfunction is associated with severe retinopathy in diabetic men. Urology 2011;77:1133-6.

12. Cho BL, Kim YS, Choi YS, Hong MH, Seo HG, Lee SY, et al. Prevalence and risk factors for erectile dysfunction in primary care: results of a Korean study. Int J Impot Res 2003;15:323-8.

13. Lu CC, Jiann BP, Sun CC, Lam HC, Chu CH, Lee JK. Association of glycemic control with risk of erectile dysfunction in men with type 2 diabetes. J Sex Med 2009;6:1719-28.

14. Siu SC, Lo SK, Wong KW, Ip KM, Wong YS. Prevalence of and risk factors for erectile dysfunction in Hong Kong diabetic patients. Diabet Med 2001;18:732-8.

15. Sasaki H, Yamasaki H, Ogawa K, Nanjo K, Kawamori R, Iwamoto Y, et al. Prevalence and risk factors for erectile dysfunction in Japanese diabetics. Diabetes Res Clin Pract 2005;70:81-9.

16. Brookes ST, Link CL, Donovan JL, McKinlay JB. Relationship between lower urinary tract symptoms and erectile dysfunction: results from the Boston Area Community Health Survey. J Urol 2008; 179:250-5.

17. Ikeda Y, Nakagawa H, Ohmori-Matsuda K, Hozawa A, Masamune Y, Nishino Y, et al. Risk factors for overactive bladder in the elderly population: a community-based study with face-to-face interview. Int J Urol 2011;18:212-8.

18. Nouwen A, Winkley K, Twisk J, Lloyd CE, Peyrot M, Ismail K, et al. Type 2 diabetes mellitus as a risk factor for the onset of depression: a systematic review and meta-analysis. Diabetologia 2010;53: 2480-6.

19. Wong SY, Woo J, Leung JC, Leung PC. Depressive symptoms and lifestyle factors as risk factors of lower urinary tract symptoms in Southern Chinese men: a prospective study. Aging Male 2010;13: 113-9.

20. Cho MJ, Kim KH. Diagnostic validity of the CES-D (Korean version) in the assessment of DSM-III-R major depression. J Korean Neuropsychiatr Assoc 1993;32:381-99.

21. Lyness JM, Conwell Y, King DA, Cox C, Caine ED. Ruminative thinking in older inpatients with major depression. J Affect Disord 1997;46:273-7.

22. Choi HR, Chung WS, Shim BS, Kwon SW, Hong SJ, Chung BH, et al. Translation Validity and Reliability of I-PSS Korean Version. Korean J Urol 1996;37:659-65.

23. Ahn TY, Lee DS, Kang WC, Hong JH, Kim YS. Validation of an abridged Korean Version of the International Index of Erectile Function (IIEF-5) as a diagnostic tool for erectile dysfunction. Korean J Urol 2001;42:535-40.

24. Rosen RC, Cappelleri JC, Smith MD, Lipsky J, Pena BM. Development and evaluation of an abridged, 5-item version of the International Index of Erectile Function (IIEF-5) as a diagnostic tool for erectile dysfunction. Int J Impot Res 1999;11:319-26.

25. Wang CC, Chancellor MB, Lin JM, Hsieh JH, Yu HJ. Type 2 diabetes but not metabolic syndrome is associated with an increased risk of lower urinary tract symptoms and erectile dysfunction in men aged < 45 years. BJU Int 2010;105:1136-40.

26. Sarma AV, Burke JP, Jacobson DJ, McGree ME, St Sauver J, Girman CJ, et al. Associations between diabetes and clinical markers of benign prostatic hyperplasia among community-dwelling Black and White men. Diabetes Care 2008;31:476-82.

27. Frimodt-Moller C. Diabetic cystopathy: epidemiology and related disorders. Ann Intern Med 1980;92(2 Pt 2):318-21.

28. Kudlacz EM, Chun AL, Skau KA, Gerald MC, Wallace LJ. Diabetes and diuretic-induced alterations in function of rat urinary bladder. Diabetes 1988;37:949-55.

29. Wang CC, Nagatomi J, Toosi KK, Yoshimura N, Hsieh JH, Chancellor $\mathrm{MB}$, et al. Diabetes-induced alternations in biomechanical properties of urinary bladder wall in rats. Urology 2009;73:911-5.

30. Kim SO, Choi HS, Kim YJ, Kim HS, Hwang IS, Hwang EC, et al. Impact of nocturia on health-related quality of life and medical outcomes study sleep score in men. Int Neurourol J 2011;15:82-6.

31. Lee WC, Wu CC, Wu HP, Tai TY. Lower urinary tract symptoms and uroflowmetry in women with type 2 diabetes mellitus with and without bladder dysfunction. Urology 2007;69:685-90.

32. Mariappan P, Chong WL. Prevalence and correlations of lower urinary tract symptoms, erectile dysfunction and incontinence in men from a multiethnic Asian population: Results of a regional population-based survey and comparison with industrialized nations. BJU Int 2006;98:1264-8.

33. El-Sakka AI. Lower urinary tract symptoms in patients with erectile dysfunction: analysis of risk factors. J Sex Med 2006;3:144-9.

34. Fitzgerald MP, Link CL, Litman HJ, Travison TG, McKinlay JB. Beyond the lower urinary tract: the association of urologic and sexual symptoms with common illnesses. Eur Urol 2007;52:407-15.

35. De Berardis G, Pellegrini F, Franciosi M, Belfiglio M, Di Nardo B, Greenfield S, et al. Longitudinal assessment of quality of life in patients with type 2 diabetes and self-reported erectile dysfunction. Diabetes Care 2005;28:2637-43. 